\title{
The Single-phase AC Regulator on Base of Bidirectional IGBT Switches
}

\author{
Vladimirs Cimanis, Riga Technical University, Vladimirs Hramcovs, Riga Technical University, \\ Ivars Rankis, Riga Technical University
}

\begin{abstract}
In the work one of the methods for regulation of sinus shape AC voltage for middle-power loads with activeinductive character is observed. Such a regulator keeping output voltage of sinus shape must be fast-reacting and work in closedloop system. It's shown, that for providing such features Buck and Boost pulse regulators can be applied. The only difference from DC pulse converters is that electronic switches in the system must be with bidirectional conductivity. For this reason an IGBT transistors can be applied with implemented in structure reverse diodes and if such two transistors are connected in series and with contrary conductivity then at activating both one of them will be in on-state. Realization of $\mathrm{AC}$ regulators with such switches is described in the work. Results of computer modeling also are given. Output voltage ripples are investigated on subject of their range and efficiency of filtering equipment on LC base. Such regulators can be applied for instance in electrical transport self supply systems.
\end{abstract}

Keywords: bidirectional semiconductor switches, harmonic distortion, insulated gate bipolar transistors, reactive power

\section{INTRODUCTION}

Ordinary method for regulation and stabilization of AC voltage is based on application of an auto-transformer. But such method is not contact-less and requires a bulk size and expensive transformer. One of possible alternative solutions for regulation and stabilization of AC single-phase voltage can be based on application of pulse regulation methods, using transistor switches, which is ordinary for DC circuits. Applying this method in AC circuits must be solved problem with bi-directional semiconductor switches.

\section{DESCRIPTION OF THE METHOD}

Let's discuss essence of step-down or Buck mode AC regulator substituting transistor switches with the ideal contact ones (Fig.1-a). Switch is operating with rather high frequency $\mathrm{f}$ and duty ratio

$$
\gamma=\frac{{ }_{i e}}{T}
$$

where: $t_{i e}$ - time when the switch is attached to terminal " 1 " (Fig.1-b); $T$ - is switching cycle $T=1 / f ; f$ - frequency. Circuit of load must be clamped and when switch is turned off position ,0”, active-inductive load's current can by-pass through clamping circuit.

If time constant of load circuit is much bigger than switching cycle time then load current at fundamental frequency $50 \mathrm{~Hz}$ of supply will be smoothed and continuous, i.e., in duration of ,0" position bigger as zero.

Averaged value of output voltage in one cycle time of switching is

$$
u_{i z(v i d)}=\frac{1}{T} \int_{0}^{t} U_{m} \sin \omega t d t=\gamma U_{m} \sin \omega t,
$$

where: $\omega-$ is angular frequency of the supply voltage, $U_{m}-$ amplitude of the input voltage. Corresponding RMS value of voltage in one switching cycle time is

$$
U_{i z}=\sqrt{\frac{1}{2 \pi} \int_{0}^{2 \pi} u_{i z(v i d)}^{2} d \omega t}=\gamma U,
$$

where: $U=U_{m} / \sqrt{2}$. If it is assumed that $\omega L_{f}<<\sqrt{R_{s l}^{2}+\omega^{2} L_{s l}^{2}}$ and $\omega L_{f}-$ is inductive impedance of filter. At the same time $1 / \omega C_{f} \gg \sqrt{R_{s l}^{2}+\omega^{2} L_{s l}^{2}}$, where $1 / \omega C_{f}$ - capacitive reactance of the filter. Then RMS value of the voltage across the load is:

$$
U_{s l} \cong \gamma U=\frac{\gamma U_{m}}{\sqrt{2}}
$$

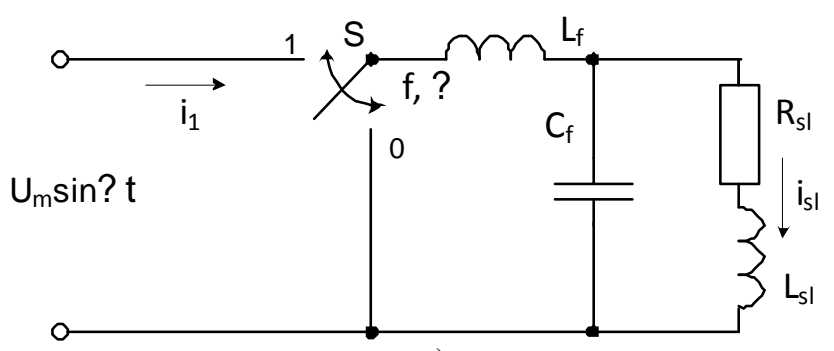

a)

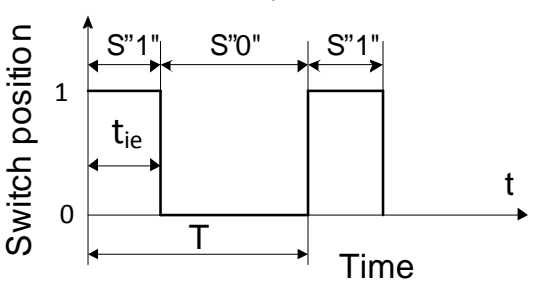

b)

Fig.1. Substitution scheme of the single-phase sinus shape voltage step-down pulse regulator (a), switching diagram of switch $\mathrm{S}(\mathrm{b})$. 


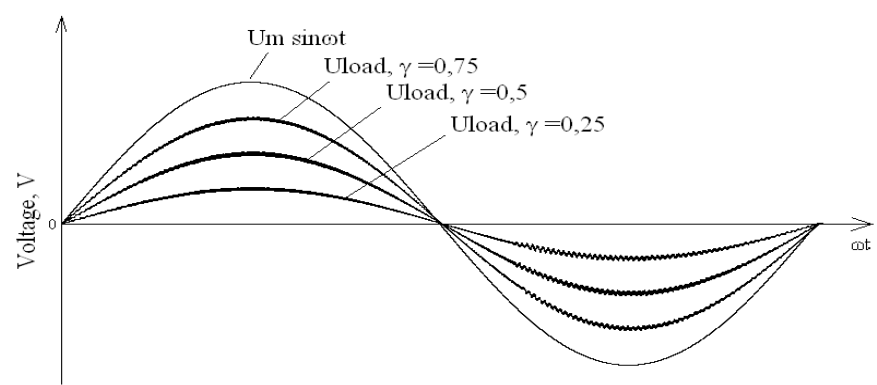

Fig.2. Voltage diagrams for step-down pulse regulator at different values of duty ratio $\gamma$.

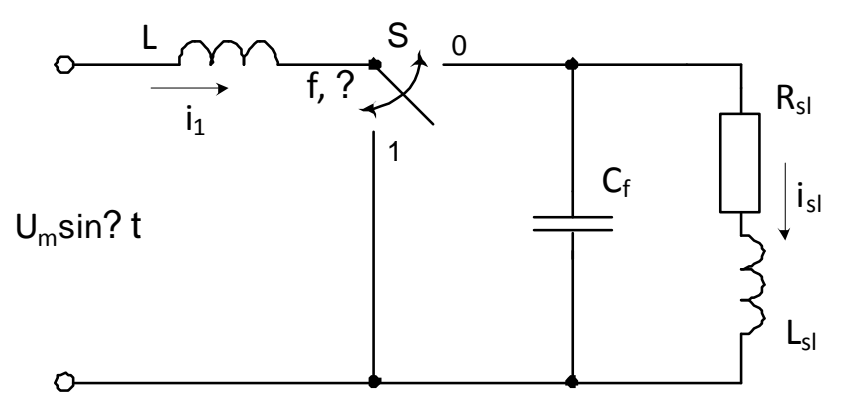

Fig.3. Substitution scheme of step-up pulse converter application for sinus shape AC voltage.

The load current then can be calculated as

$$
I_{s l}=\frac{\gamma U}{\sqrt{R_{s l}^{2}+\omega^{2} L_{s l}^{2}}},
$$

where $R_{s l}$ - resistance of the load, $L_{s l}-$ its inductance.

Similarly as for DC pulse regulators, there are possible several variants for realization of the duty ratio $\gamma$ variations. If switching frequency is constant, then $\gamma$ can be changed increasing or decreasing duty time duration in turned-on position ,1" of the switch $\mathrm{S}$. Such realization is nominated as Pulse Width Modulation (PWM). This is most applied regulation method results on using it for sinus shape voltage diagrams at different values of $\gamma$ are presented in Fig.2.

If switch is connected in parallel to source through inductance L, which is applied as energy storage device, then it's possible to obtain voltage step-up pulse regulator (Fig.3).

Using RMS values of AC voltage at neglecting of losses in pulse regulator, load voltage can be calculated as

$$
U_{s l}=\frac{U}{1-\gamma} .
$$

In the case similarly as for step-down regulator, effect can be obtained at variations of duty time duration of position ,1" of switch $\mathrm{S}$ in switching cycle and voltage diagrams at different $\gamma$ will be in accordance with presented in Fig.4.

Because each source has itself an active resistance and inductance then source voltage $U_{m} \times \sin \omega t$ really begins decrease and voltage of load cannot increase to endless value.

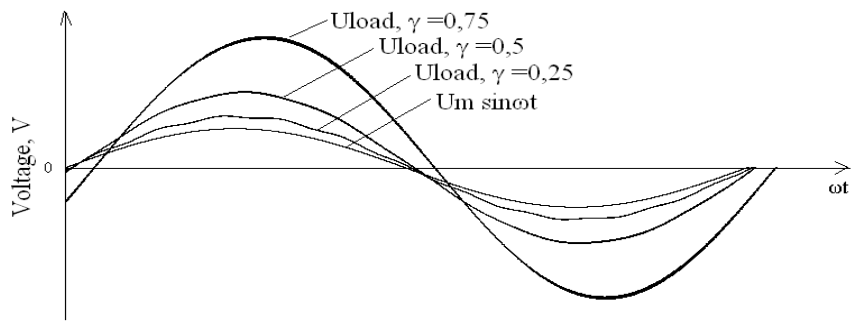

Fig.4. Diagrams of output AC voltage of step-up pulse regulator at different values of duty ratio $\gamma$.

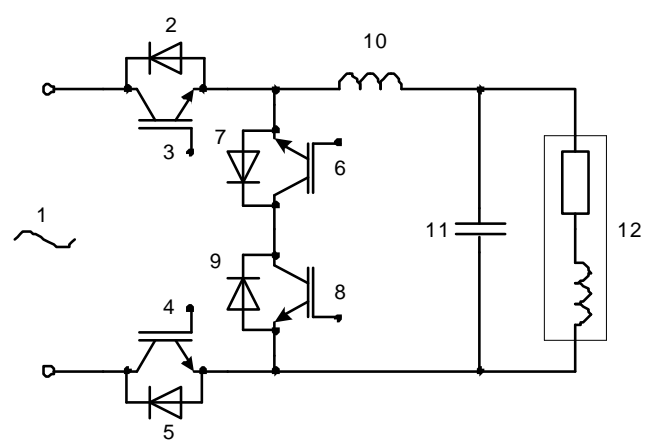

Fig.5. Scheme of single-phase voltage step-down pulse regulator.

Then the load voltage can be found as

$$
\dot{U}_{s l}=\dot{U}_{0-}\left(\frac{\dot{I}_{s l} \mathrm{Z}_{1}}{1-\gamma}\right),
$$

where $Z_{1}$ is complex impedance of source, $U_{0}-$ no-load voltage. It is possible to conclude that

$$
\frac{\dot{U}_{s l}}{\dot{U}_{0}}=\frac{1-\gamma-k}{(1-\gamma)^{2}},
$$

where $k=\stackrel{\bullet}{I}_{s l} \mathrm{Z}_{1} / \dot{U}_{0}$. Based on this equation the maximum of voltage can be estimated.

Generally sinus shape voltages in Fig.4 are mutually shifted by phase as it can be seen from above given expressions $(7,8)$ with complex numbers.

\section{REALIZATION OF AC PULSE REGULATORS}

For practical realization of pulse regulator must be applied IGBT transistors with freewheeling diodes.

Pulse regulation is obtained so, that in AC circuit are inserted two transistors in series but with opposite direction of conductivity, but in parallel to load also are inserted same configuration of transistors. Control power of transistors is small and therefore best way is activate both counterconnected transistors with common for the both control pulse (Fig.5). Load circuit is operating from L-C filter. 


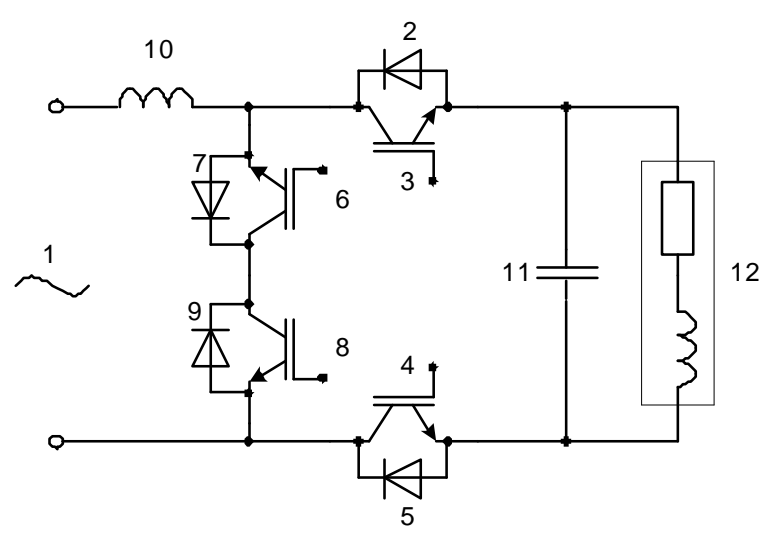

Fig.6. Scheme of the single-phase voltage step-up pulse regulator.

Contrary conducting transistors 3, 4 are inserted in series in AC circuit, each of them are clamped with reverse diodes respectively 2 and 5 . In the common circuit of mentioned transistors and load 12 a reactor 10 is inserted, but in parallel to the load - capacitor 11 , forming with the reactor an L-C output filter. In parallel to circuit of the reactor and capacitor two more contrary conducting transistors 6 and 8 with reverse diodes respectively 7 and 9 are introduced.

Regulator is working in such way, that when voltage of source is bigger than rated one, control pulse generation junction is sending alternately high frequency pulses to the transistors 3, 4 and to 8,6 . When pulses are applied to transistors 3,4 , then not dependent on polarity of AC voltage the filter circuit is connected to the supply source and current in circuit by absolute meaning is rising. If current is passing through transistor 3 , then simultaneously diode 5 is also conducting; if in other half cycle current is passing through transistor 4 , then diode 2 is also conducting.

When control pulses are disconnected from transistors 3,4 , transistors 6,8 are activated simultaneously, providing not dependently on direction of current clamping way for reactor 10 current. If reactor's current is passing on capacitor, then current is passing through transistor 6 and diode 9; if direction of reactor's current is opposite then transistor 8 and diode 7 .

If voltage across a load is not sufficiently high then longer pulses are applied to transistors in source circuit 3,4 , but to 6 , 8 - shorter. If voltage across load is too large then pulse duration for transistors 3,4 is shortened, but for $6,8-$ increased. In such way stabilization of load voltage level is provided.

If transistors are switched with much higher frequency than rated frequency of supply source then because of filter operation voltage of its capacitor 11 is practically of sinus shape.

If supply voltage is smaller than rated value of load voltage then control pulses are applied alternatively to transistors 6,8 and 3, 4 (Fig.6). Independently from polarity of source voltage reactor 10 through transistor 8 , diode 7 or transistor 6 , diode 9 is connected to the source terminals and electromagnetic energy is stored in the reactor. When control of transistors 6,8 is deactivated control of transistors 3,4 is activated and independently on polarity of current in reactor 10 the later is inserted in series with load. As result voltage of capacitor 11 is increasing as also load voltage. If load voltage is smaller than longer transistors 6,8 are activated in switching cycle but shorter time duration - transistors 3 , 4. If load voltage is rising above preset value then transistors 3,4 are activate longer, but 6,8 - shorter. In such way load voltage is stabilized.

\section{COMPUTER SIMULATION OF THE SCHEME}

Computer simulation is provided using simulation package PSIM which allow provide simplified simulations. As it is seen from diagrams Fig.8 and Fig.9 ripples of output voltage are bigger at smaller parameters (capacitance and inductance) of output filter.

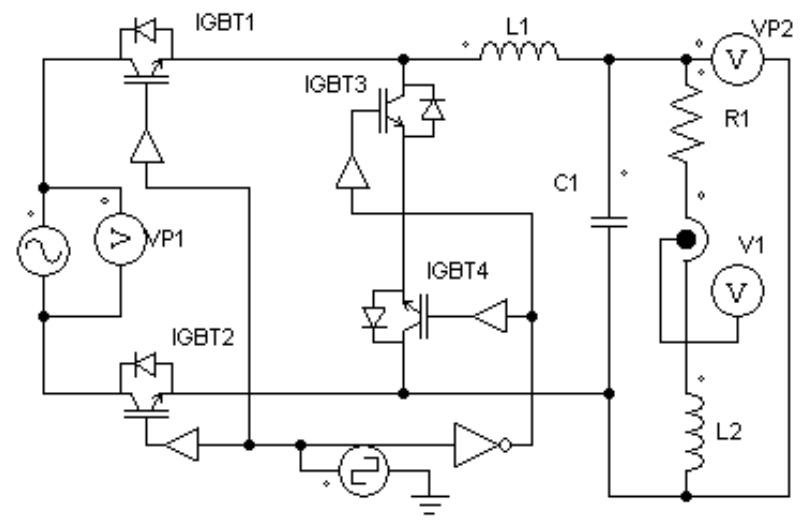

Fig.7. Scheme of computer simulation of step-down pulse converter at $\cos \varphi=0,8$ and active power of load $\mathrm{P}=1,5 \mathrm{~kW}$, keeping duty ratio $\gamma=0,5$, $\mathrm{U}_{\text {baroš }}=220 \mathrm{~V}$, switching frequency $=50 \mathrm{kHz}$.

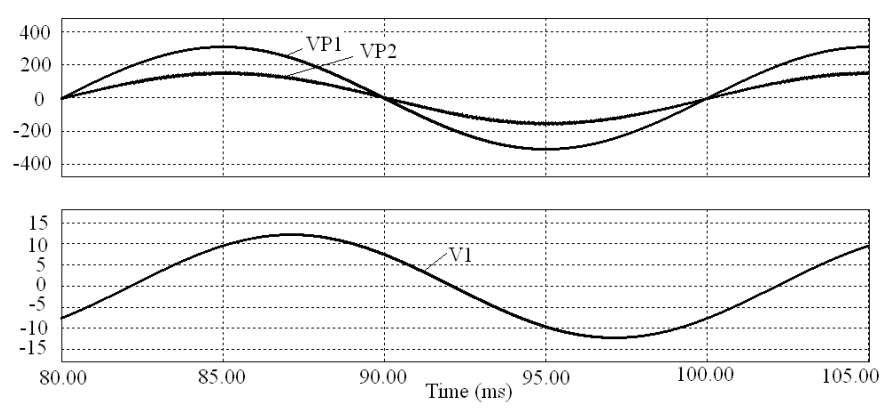

Fig.8. Modeling of step-down pulse regulator at parameters of filter $\mathrm{L} 1=1 \mathrm{mH}$ and $\mathrm{C} 1=0,5 \mu \mathrm{F}$.

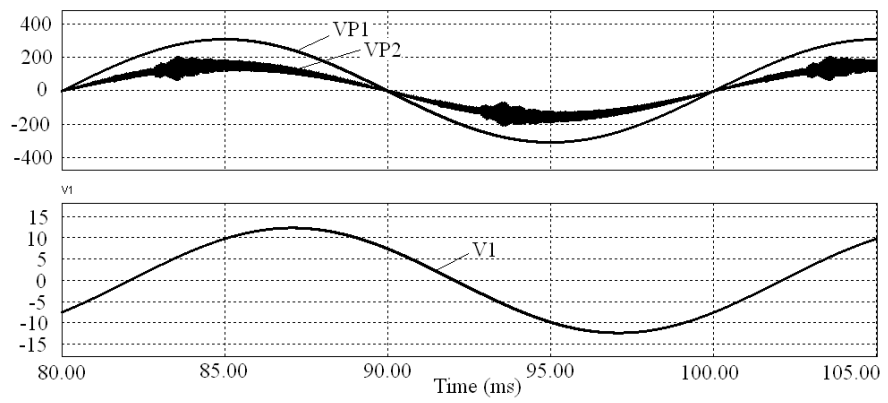

Fig.9. Diagrams of voltages and currents for step-down pulse regulator at parameters of filter $\mathrm{L} 1=0,2 \mathrm{mH}$ and $\mathrm{C} 1=0,5 \mu \mathrm{F}$. 


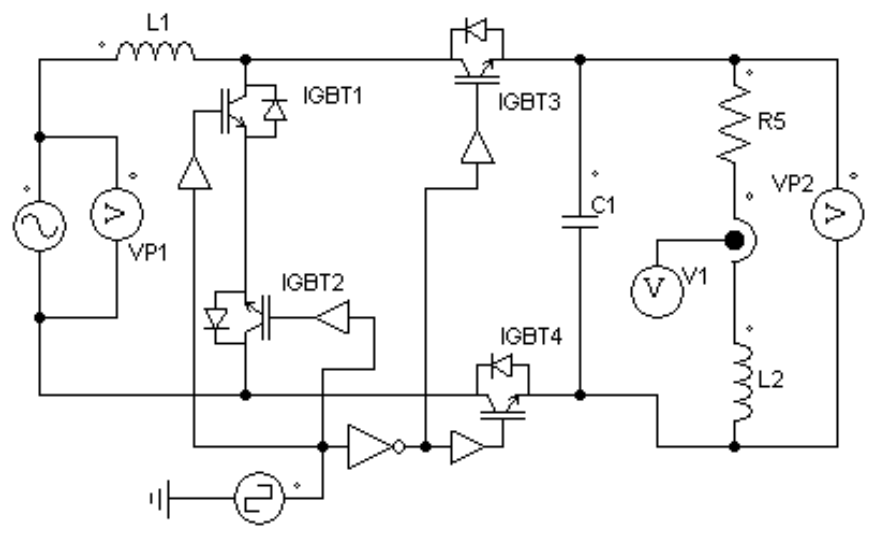

Fig.10. Computer modeling scheme for step-up pulse regulator at load's $\cos \varphi=0,8$ and its active power $\mathrm{P}=2,5 \mathrm{~kW}$, duty ration $\gamma=0,5, \mathrm{U}_{\text {baroš }}=110 \mathrm{~V}$.

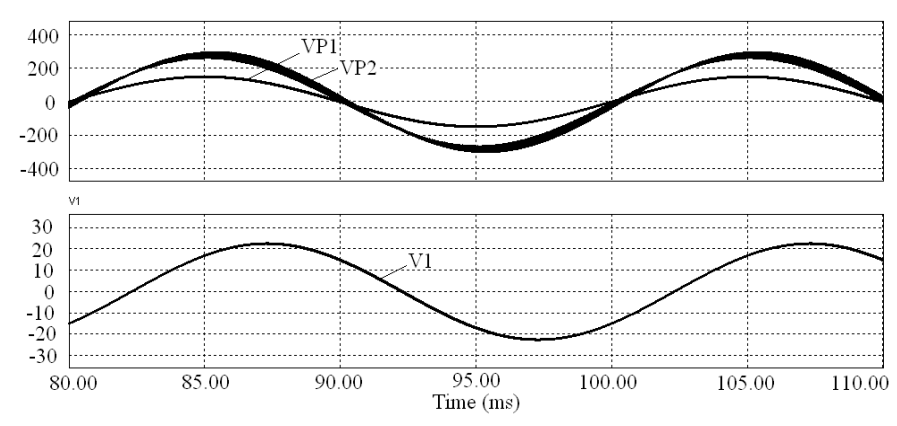

Fig.11. Simulation diagrams for step-up pulse regulator at capacitance $\mathrm{C} 1=5 \mu \mathrm{F}$.
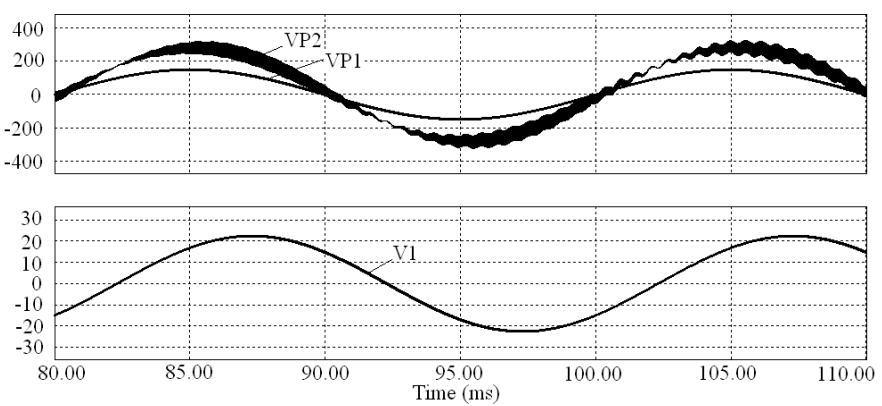

Fig.12. Simulation diagrams for step-up pulse regulator at capacitance $\mathrm{C} 1=2,5 \mu \mathrm{F}$.

\section{V.CONCLUSIONS}

1. Schemes for step-down and step-up pulse regulators of the AC sinus shape voltage are elaborated using as base switches an IGBT transistors connected in contrary conduction direction and controlled by simplified algorithm.

2. Computer simulation of elaborated high-frequency schemes approved possibility to construct an industrial pulse regulators on its base for supply of middle-power loads.

3. Synthesizing stabilizer on base of created schemes output of converter must be supported by filter which must be constructed taking into account quality of output voltage for accepted load at all deviations of input $\mathrm{AC}$ voltage values.

\section{REFERENCES}

[1] Muhammad. H. Rashid. (Editor in Chief>, Academic Press). Power electronics handbook. 2007.-1172lpp.

[2] Mohan N., Undeland T., Robbins W. Power Electronics: Converters, Application, Design. - NY: John Wiley and sons, 1989, 667 pp.

[3] Idir, N. Franchaud, J.J. Bausiere, R., "Active Gate Voltage Control of Bidirectional Switches used in AC-AC Converters", Power Electronics Specialists Conference, 2007. PESC 2007, IEEE, 690 - 695

[4] Jin Nan Tang Hou-jun Liu Wei Ye Peng-sheng, "Analysis and control of Buck-Boost Chopper type AC voltage regulator", 1019 - 1023

[5] Kragh, H., "On the control of a DC-link based high frequency ACvoltage regulator", Power Electronics Specialists Conference, 2001. PESC. 2001 IEEE 32nd Annual, 1122 - 1128 vol.2

[6] Ju-Sung Kang Ahmed, N.A. Kwang-Joo Choi Hyun Woo Lee Mutsuo Nakaoka, "Pulse modulated AC voltage regulator using bidirectional active switches with different control strategies", 1107 - 1111 Vol. 2

[7] Raṇķis I. Energoelectronics.- RTU Izdevniecība, 2004.-160 lpp.

[8] Latvian Patent Nr 13835 Stabilizer of the Sinus Shape AC voltage/ V.Hramcovs, V.Cimanis, I.Rankis, 2009

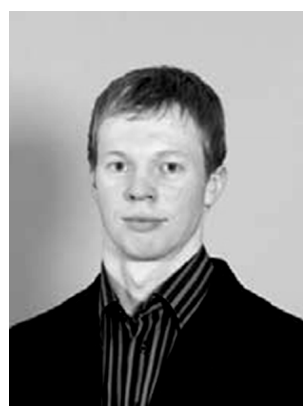

Vladimirs Cimanis, doctoral student, M.Sc. Started study in Riga Technical University (RTU) in 2001 and has got a bachelor's (B.Sc.) degree and engineer's qualification in mechatronics in 2004. In 2006 has got a master's (M.Sc.) degree and electrical engineer qualification. Since 2006 works as a design engineer at JSC "Riga Electric Machine Building Works" and as a research assistant at RTU. Currently he is a doctoral student of RTU at "Computer control of electrical technologies" study program.

Address: Kronvalda boulevard 1, LV1050, Riga, Latvia, Phone: +371 29679741, e-mail: vladimirs.cimanis@rtu.lv

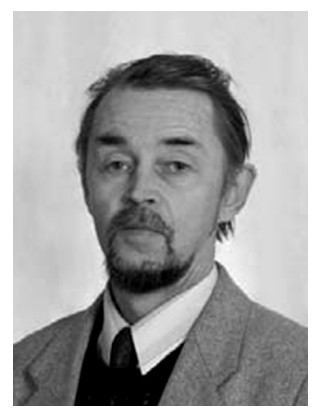

Vladimirs Hramcovs, professor, Dr.Sc.Eng. graduated from Leningrad Institute of Engineers of Railway Transportation as electromechanical engineer in 1973. After defending the dissertation in Moscow in 1983 got a Dr.Sc. academic degree. In 1992 at scientific advisory committee of Riga Technical University (RTU) has been assigned Dr.Sc.Ing. degree. Until 1986 worked as workshop chief, engineering group head and research engineer at railway transport structural institutions and research organizations. Since 1986 works as professor at Faculty of Power and Electrical Engineering (FPEE) (RTU). 1986 - 2004 - assistant professor of Department of Electronics and Electrical Engineering. 2004 - 2009 - associate professor of Department of Electronics and Electrical Engineering. Currently is a professor of RTU FPEE Department of Electronics and Electrical Engineering.Research field is associated with application of power electronics in electrical transport and technical diagnosis of its equipment.

Address: Meza street1, LV1048, Riga, Latvia, Phone: +371 67089503, e-mail: vladimirs.hramcovs@rtu.lv

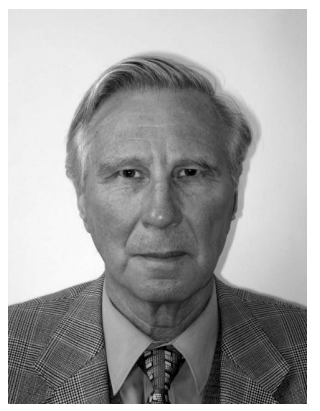

Ivars Rankis, professor, Hab.Dr.sc.eng. He graduated from Riga Polytechnic institute in 1960 as engineer-electro-mechanic. Defended his first degree of Dr. Sc. (candidate of technical sciences) in 1970. Defended his second degree Hab.Dr.sc.eng. in 1992 at Riga Technical university. From 1958-1966 he worked as engineer at Riga Electrical machine building company. From 1966 he started studies as doctoral student, but from 1970 - as teacher of different subjects of electrical engineering at Riga Technical university. Research interests are connected with Power electronics and Industrial automation. Now is professor at department of Industrial electronics and electrical technologies of Riga Technical university.

Address: Kronvalda 1, LV1048,Riga, Latvia, Phone: +371 67089 917, rankis@eef.rtu.lv 